\title{
O Consentimento Livre e Esclarecido na JURISPRUDÊNCIA DOS TribUNAIS BRASILEIROS ${ }^{(*)}$
}

\author{
INFORMED CONSENT IN THE BRAZILIAN CASE LAW
}

Gabriela Guz(**)

\section{RESUMO}

O consentimento livre e esclarecido corresponde à concretização do respeito à autonomia do paciente na prática de assistência médica, representando profunda mudança de paradigma para a relação médico-paciente. A bioética e os tribunais estadunidenses concorreram para o seu nascimento e desenvolvimento. Entretanto, a maneira como os tribunais delinearam o tema acabou por reduzi-lo ao cumprimento dos deveres de obter o consentimento do paciente e de informá-lo. Além disso, a popularização dos formulários com informações padronizadas para fins de prova documental distanciou o tema de seu originário fundamento. No Brasil, o consentimento livre e esclarecido foi primeiramente desenvolvido pela Bioética e, apenas recentemente, passou a se esboçar a abordagem jurídica do tema. No que se refere a sua abordagem pelos tribunais brasileiros, verificou-se em levantamento jurisprudencial que a temática do consentimento livre e esclarecido faz-se presente nos tribunais fundamentalmente em função do questionamento sobre o dever de informar do médico. Tal questionamento, por sua vez, mostra-se impulsionado pela aplicação do Código de Defesa do Consumidor à relação médico-paciente. Assim, são aspectos da legislação consumerista, como a utilização de um padrão objetivo de informação, que vão delinear a abordagem dos tribunais brasileiros sobre o consentimento livre e esclarecido na prática de assistência médica. A aceitação e até mesmo a exigência da utilização de formulários padronizados foram verificadas em diversas decisões obtidas. Há indícios, portanto, de que a abordagem judicial do consentimento livre e esclarecido no Brasil está seguindo o caminho trilhado pela jurisprudência estadunidense.

$\left(^{*}\right)$ Artigo elaborado a partir da dissertação de mestrado apresentada na Faculdade de Saúde Pública da Universidade de São Paulo sob o título: 'O consentimento livre e esclarecido na prática de assistência médica: um estudo da jurisprudência dos tribunais brasileiros'.

$\left.{ }^{(* *}\right)$ Advogada, especialista em Bioética pela Faculdade de Medicina da Universidade de São Paulo, mestre em Saúde Pública pela Faculdade de Saúde Pública da Universidade de São Paulo. E-mail: <gabrielaguz@uol.com.br>. Recebido em 14.09.09. Aprovado em 13.01.10. 


\section{Palavras-chave}

Bioética; Ética Médica; Relação Médico-Paciente.

\section{ABSTRACT}

Informed consent corresponds to the concretion of the respect for patient's autonomy in medical care practice, representing a deep change of paradigm to the doctor-patient relationship. Bioethics and American courts had concurred for its birth and development. However, the way informed consent has been delineated by the courts has restricted it to the fulfillment of the legal duties to obtain patient's consent and to disclose information. Moreover, the popularization of consent forms containing standardized information for the purpose of evidence of the fulfillment of such duties has moved informed consent away from its original foundation. In Brazil, informed consent was first developed by Bioethics and only recently the legal approach has started to emerge. Regarding its approach by the Brazilian courts, it was verified in a study of case law that informed consent is a reality in such courts, basically due to the questioning on the doctor's duty to disclose information. Such questioning is based on the application of the Consumer's Statute to the doctor-patient relationship. Thus, Consumer's Statute aspects - such as the use of an objective standard of information and the focus in the protection of the consumer - have delineate the understanding of the Brazilian courts on informed consent in medical care practice. The acceptance and even the requirement of the standardized forms utilization were mentioned in many of the obtained decisions. Therefore, there are indications, that the judicial approach of informed consent in Brazil is following the path trod by the American case law.

\section{Keywords}

Bioethics; Doctor-patient Relationship; Medical Ethics.

\section{A VALORIZAÇÃO DO RESPEITO À AUTONOMIA DO PACIENTE(1)}

A relação médico-paciente foi marcada, ao longo da história da medicina, pelo poder decisório do médico sobre a saúde do paciente e, consequentemente, pela desconsideração da vontade deste no processo de tomada de decisão sobre a própria saúde.

(1) O vocábulo 'paciente' está sendo aqui utilizado em seu sentido original (do latim patiens: aquele que sofre, que padece). 
Nesse sentido, $\mathrm{Katz}^{(2)}$ ressalta que "nunca foi parte da essência da medicina a ideia de que os pacientes têm direito a um pouco de liberdade, a compartilhar as cargas da decisão com seus médicos".

A partir do século $X X$, inicia-se um processo de crescente ascendência do respeito à autonomia individual sobre o paternalismo e autoritarismo médico, fato que acaba por acarretar na "mais radical reorientação na longa história da tradição hipocrática"(3).

Schraiber ${ }^{(4)}$ destaca a introdução de intermediários nas relações entre médicos e pacientes como fatores desencadeantes do processo de despersonalização que gradualmente atingiu a medicina do século $X X$, citando como exemplos de tais intermediários a tecnologia e seus equivalentes nas esferas da organização e comercialização dos serviços médicos: a empresa, os seguros-saúde, o Estado.

Esse processo de desumanização da prática médica teve papel fundamental no surgimento da disciplina Bioética na década de 1970, e na progressiva valorização da autonomia individual que se verificou, a partir de então, no contexto da assistência em saúde.

Callahan ${ }^{(5)}$ observa, assim, que a tomada de decisão foi a grande questão do início do desenvolvimento da Bioética. De acordo com Diniz e Guilhem(6), formou-se "(...) até mesmo um certo consenso entre as mais variadas correntes teóricas da bioética de que a preservação da autonomia de cada indivíduo, e aí se incluem suas opções morais sobre os padrões de bem-viver, deveria ser um dos carros-chefes da disciplina".

Para Fortes ${ }^{(7)}$, respeitar a autonomia do paciente no âmbito da assistência em saúde significa:

(...) reconhecer que cada pessoa possui pontos de vista e expectativas próprias quanto ao seu destino, e que é ela quem deve deliberar e tomar decisões seguindo seu próprio plano de vida e ação, embasadas em crenças, aspirações e valores próprios, mesmo quando estes divirjam dos valores dos profissionais de saúde ou dos dominantes na sociedade. Afinal, cabe sempre lembrar que o

(2) KATZ, J. El médico y el paciente: su mundo silencioso. México, D.F.: Fondo de Cultura Económica, 1989. p. 36, tradução livre.

(3) Pellegrino apud ALMEIDA, J. L. T. Respeito à autonomia do paciente e consentimento livre e esclarecido: uma abordagem principialista da relação médico-paciente. 1999. p. 68. Tese (Doutorado em Ciências) — Fundação Oswaldo Cruz, Escola Nacional de Saúde Pública, Rio de Janeiro, 1999.

(4) SCHRAIBER, L. B. Medicina tecnológica e prática profissional contemporânea: novos desafios, outros dilemas. 1997. p. 168. Tese (Livre Docência - Departamento de Medicina Preventiva) Faculdade de Medicina, Universidade de São Paulo, São Paulo, 1997.

(5) CALLAHAN, D. Bioethics and the culture wars. Cambridge Quarterly of Healthcare Ethics, New York, v. 14, n. 4, 2005.

(6) DINIZ, D.; GUILHEM, D. O que é bioética. São Paulo: Brasiliense, 2002. p. 28.

(7) FORTES, P.A.C. Ética e saúde. São Paulo: EPU, 1998. p. 39-40. 
corpo, a dor, o sofrimento, a doença são da própria pessoa e que violar a autonomia significa tratar as pessoas como meios e não como fins em si mesmas.

Nesse contexto, a valorização do respeito à autonomia está diretamente relacionada à tomada de decisão sobre a própria saúde, de tal sorte que implica reconhecer-se que:

O conhecimento sobre fatos médicos não é suficiente. Compradores sábios contratam um engenheiro para avaliar uma casa velha, mas poucos permitirão que o engenheiro escolha a casa a ser comprada. O fato de ser engenheiro não possibilita a este profissional decidir qual casa uma família deve comprar porque ele não tem conhecimento sobre o padrão de vida da família, os gostos pessoais, e o potencial de crescimento da mesma. Os profissionais de saúde não podem deduzir cientificamente o melhor tratamento para um determinado paciente simplesmente baseados em fatos médicos. O que é considerado importante pelos indivíduos depende de seu estilo de vida, experiências passadas e valores. Assim, escolher a terapia ideal não é uma questão estritamente objetiva. ${ }^{(8)}$

É nesse contexto que o consentimento livre e esclarecido(9), enquanto desdobramento da concepção de respeito à autonomia do paciente, irá representar o rompimento com o tradicional poder decisório do médico ${ }^{(10)}$.

\section{O PROCESSO DE DECISÃO LIVRE E ESCLARECIDA}

consentimento livre e esclarecido corresponde, essencialmente, a um novo modelo de tomada de decisão no contexto da saúde individual que, ao fundamentar-se no respeito à autodeterminação do paciente, traz profundas alterações à própria dinâmica da relação médico-paciente, tradicionalmente pautada no poder de decisão do médico.

Isso porque, nesse novo modelo, passam a ser fundamentais para a tomada de decisão não apenas as informações técnicas detidas pelo

(8) ARNOLD, R.M.; LIDZ, C.W. Informed consent - Clinical aspects of consent in healthcare. In: POST, S. G. Encyclopedia of bioethics. 3. ed. New York: Macmillan Reference, 2003. v. 3, p. 1291, tradução livre.

(9) Como se verificará mais adiante, a expressão originariamente concebida nos Estados Unidos para se referir ao tema do presente estudo corresponde a 'informed consent' ('consentimento informado'). Entretanto, adotar-se-á aqui a expressão brasileira 'consentimento livre e esclarecido'. Dessa forma, apenas quando nos referirmos ao informed consent no contexto estadunidense, mencionaremos o tema através da expressão 'consentimento informado'.

(10) A despeito de se focar a relação entre médico e paciente, muito do que aqui se dirá também é aplicável aos demais profissionais da área de saúde, uma vez que também faz parte de sua rotina profissional a questão da tomada de decisão no contexto da assistência em saúde.

(11) PRESIDENT'S COMISSION FOR THE STUDY OF ETHICAL PROBLEMS IN MEDICINE AND BIOMEDICAL AND BEHAVIORAL RESEARCH. Making health care decisions: the ethical and legal implications of informed consent in the patient-practitioner relationship. Washington, 1982. v. 1, p. 38, tradução livre. 
profissional médico, mas, especialmente, a consideração dos valores, expectativas, desejos e crenças do próprio paciente.

É por essa razão que o consentimento livre e esclarecido pressupõe a troca de informações entre o profissional e o paciente, de maneira que "o médico ou outro profissional de saúde chama o paciente a participar de um diálogo, no qual o profissional busca ajudar o paciente a compreender a situação médica e os cursos de ação disponíveis, e o paciente traz as suas preocupações e desejos"(11).

A troca de informações pode ser considerada, pois, um "caminho de duas vias"(12). Implica que o paciente propicie ao médico o conhecimento sobre suas angústias, dúvidas, prioridades, necessidades e valores e, de outro lado, que o médico esclareça ao paciente os caminhos possíveis a serem seguidos, e as características de cada um desses caminhos.

Kuczewski e Meisel ${ }^{(13)}$ observam que a interação humana é fundamental nesse processo de tomada de decisão, de tal sorte que os diálogos entre médicos e pacientes “(...) devem ajudar o paciente a receber a informação, fazer perguntas, dar informações, dizer 'quero pensar sobre isso' ou 'pensei sobre isso e não consegui tomar uma decisão. O que você acha que eu devo fazer?".

É essencial, assim, não apenas transmitir a informação ao paciente, mas especialmente certificar-se de que ele entendeu o que lhe foi transmitido, para que, a partir do esclarecimento, o paciente possa expressar os seus questionamentos e caminhos preferenciais. Dessa concepção decorre a consolidação no Brasil da expressão 'consentimento livre e esclarecido', inspirada pela jurisprudência francesa, que cunhou a expressão 'consentement éclairé'(14).

Cabe ressaltar ainda que o consentimento livre e esclarecido, enquanto um processo compartilhado de tomada de decisão, pode apresentar diversos resultados. Assim, o 'consentimento' a uma das propostas apresentadas pelo médico constitui uma entre as várias possibilidades de decisão pelo paciente.

Isso porque o paciente poderá ainda recusar a realização de determinado procedimento, como também consentir na realização de tratamento alternativo proposto pelo médico. Poderá, ainda, recusar todas as alternativas propostas, ou, ainda, recusar-se a tomar uma decisão, requerendo que o profissional decida por ele.

(12) APPELBAUM, P.; LIDZ, C.W.; MEISEL, A. Informed consent: legal theory and clinical practice. New York: Oxford University Press, 1987.

(13) KUCZEWSKI, M.; MEISEL, A. Demystifying myths about informed consent. Forum - Risk Management Foundation of the Harvard Medical institutions, Cambridge, v. 20, n. 4, p. 2, summer 2000, tradução livre.

(14) VIEIRA, S; HOSSNE, W. S. Experimentação com seres humanos. 2. ed. São Paulo: Moderna, 1987. 
Durante o processo de troca de informações, o paciente também pode recusar-se a receber determinados tipos de informação - ou, ainda, recusar-se a receber todo e qualquer tipo de informação. O desejo informacional do paciente deve, pois, ser respeitado, servindo de baliza ao médico.

Observa-se, assim, que o processo contínuo de decisão pode acarretar diversas formas de 'consentimentos livres e esclarecidos' e 'recusas livres e esclarecidas', de tal sorte que, em verdade, trata-se, de uma decisão livre e esclarecida.

\section{OS TRIBUNAIS ESTADUNIDENSES E A CRIAÇÃO DO 'INFORMED CONSENT'}

A temática do respeito à autodeterminação do paciente já se desenvolvia no âmbito judicial estadunidense desde o início do século XX, especialmente em função do crescente processo de desumanização que se verificava na medicina, e da consequente crise de confiança que se instaurava entre médicos e pacientes.

Assim, já no ano de 1914 é proferida, pela Corte de Nova York, a decisão tida como precursora do reconhecimento da autodeterminação do paciente (caso Schloendorff versus The Society of the New York Hospital). $\mathrm{Na}$ referida decisão, reconheceu o Juiz Cardozo que "todo ser humano em idade adulta e mentalmente capaz tem o direito de determinar o que será feito em seu próprio corpo"(15).

Verifica-se, pois, que foram as decisões judiciais proferidas nas crescentes ações de responsabilidade médica, especialmente a partir da década de 1950, que acabaram por desenvolver a doutrina do 'consentimento informado' nos Estados Unidos. Observa-se, inclusive, que a própria expressão 'informed consent' (consentimento informado), foi criada no contexto judicial estadunidense no ano de 1957.

Ocorre que o desenvolvimento da doutrina do consentimento informado no âmbito judicial da responsabilidade civil médica acabou por reduzir a temática ao cumprimento de dois deveres médicos: o de informar o paciente e o de obter o consentimento deste previamente a um procedimento médico.

Segundo $\mathrm{Katz}^{(16)}$ :

Para se distinguir entre o que os juízes estadunidenses fizeram e o que pretenderam fazer, deve-se traçar acentuadas diferenças entre a doutrina legal, como promulgada pelos juízes, e a ideia de consentimento informado, baseada no comprometimento com a autodeterminação individual.

(15) FADEN, R. R; BEAUCHAMP, T. L. A history and theory of informed consent. New York: Oxford University Press, 1986.

(16) KATZ, J. op. cit., p. 24-25, tradução livre. 
O mesmo autor, citado por Beauchamp e Childress ${ }^{(17)}$, ressalta que os tribunais estadunidenses "permitiram que a ideia do consentimento informado (...) morresse gradualmente", de tal sorte que "uma obrigação judicialmente imposta deve ser distinguida da ideia do consentimento informado, ou seja, da ideia de que os pacientes têm um papel decisivo a desempenhar no processo da decisão médica".

Referidas críticas realizadas por Katz referem-se ao hiato entre os dois sentidos que o 'consentimento informado' passou a ter: o de um processo de decisão, pautado no respeito à autonomia individual, e o de um evento, caracterizado mais pela preocupação com o cumprimento de deveres padronizados de informação e consentimento, e menos com o processo de decisão em si e com a autodeterminação individual.

Segundo Appelbaum e col.(18), na abordagem do consentimento livre e esclarecido enquanto um evento, a compreensão das informações pelo paciente é questão menos importante do que o fornecimento das informações pelo médico.

O termo de consentimento informado'(19) — formulário padronizado contendo as informações legalmente exigidas, bem como a assinatura do paciente - , corresponde, assim, ao símbolo central do modelo da abordagem do tema como um evento.

Via de regra, a adoção do 'termo' no contexto da assistência médica tem o intuito de documentar o cumprimento, pelo médico, do dever de obter o consentimento do paciente e/ou de informá-lo, para fins de suposta proteção do profissional contra uma eventual responsabilização por descumprimento dos mencionados deveres ${ }^{(20)}$.

Embora a obtenção do 'termo de consentimento informado' não tenha sido imposta aos médicos pelos tribunais estadunidenses, tal formulário tampouco foi afastado, pelos tribunais, como prova de ter havido o cumprimento dos deveres de informar e de obter a autorização pelo médico.

Dessa forma, a utilização do 'termo de consentimento informado' como forma de prevenção de responsabilização jurídica popularizou-se de tal maneira que "(...) aquilo que era para ser um processo de diálogo e discussão transformou-se em um evento no qual papéis são assinados e requisitos legais mínimos são satisfeitos"(21).

(17) BEAUCHAMP, T. L.; CHILDRESS, J. F. Princípios de ética biomédica. Tradução de L. Pudenzi.

São Paulo: Loyola, 2002, p. 164-165.

(18) APPELBAUM, P.; LIDZ, C.W.; MEISEL, A. op. cit.

(19) No Brasil, o 'termo de consentimento informado' (consent form ou informed consent form) é denominado 'termo de consentimento livre e esclarecido'.

(20) ALI, V. Consent forms as part of the informed consent process: moving away from "medical Miranda". Hastings Law Journal, San Francisco, jul. 2003.

(21) Appelbaum e col. apud ALI, V. op. cit., tradução livre. 
Beauchamp e Childress ${ }^{(22)}$ ressaltam que “(...) é essencial que se entenda o consentimento informado como um processo que ocorre com o tempo, e que se evite a visão comum de que um formulário de consentimento assinado é a essência do consentimento informado".

Entretanto, Faden e Beauchamp ${ }^{(23)}$ mencionam que pesquisas conduzidas nos Estados Unidos no início da década de 1980 indicaram que a maioria dos médicos entendia o 'consentimento informado' como um termo assinado ou simplesmente como o dever de informar.

No mesmo sentido, o relatório 'Making Health Care Decisions', elaborado nos Estados Unidos pela Comissão Presidencial para o Estudo dos Problemas Éticos na Medicina e na Pesquisa Biomédica e Biomédica Comportamental, no ano de 1982, e que tratou das 'implicações éticas e legais do consentimento informado na relação profissional-paciente', reconheceu que ${ }^{(24)}$ :

A realidade das decisões judiciais sobre o consentimento informado ficou aquém do comprometimento com o valor da autodeterminação pretendido pelo Direito. À medida que 'os tribunais impuseram aos médicos fundamentalmente um dever-de-advertir', impedindo, assim, o reconhecimento judicial da proposição de que os pacientes têm um papel decisivo a desempenhar no processo de tomada de decisão, eles simplesmente reforçaram 'o tradicional monólogo médico de falar para e não com os pacientes'

Faden e Beauchamp ${ }^{(25)}$ observam que, apesar de sua importância histórica, as decisões judiciais proferidas pelos tribunais estadunidenses não provocaram grandes mudanças nas rotinas diárias da relação médicopaciente. Isso porque "(...) o consentimento informado na prática de assistência em saúde é primeiramente um problema ético, e não jurídico”.

\section{O CONSENTIMENTO LIVRE E ESCLARECIDO NO BRASIL}

Ao contrário do que aconteceu nos Estados Unidos, onde até a criação da expressão informed consent ocorreu no ambiente judicial, verifica-se que, no Brasil, a temática do consentimento livre e esclarecido foi introduzida pela Bioética, e não pelo Direito.

A Bioética chegou ao Brasil na década de 1990. Além de sua crescente legitimação enquanto disciplina acadêmica, a Bioética no Brasil vem

(22) BEAUCHAMP, T. L.; CHILDRESS, J. F. op. cit., p. 163.

(23) FADEN, R. R; BEAUCHAMP, T. L. op. cit.

(24) PRESIDENT'S COMISSION FOR THE STUDY OF ETHICAL PROBLEMS IN MEDICINE AND BIOMEDICAL AND BEHAVIORAL RESEARCH, cit., p. 29-30.

(25) FADEN, R. R; BEAUCHAMP, T. L. op. cit., p. 141-142, tradução livre. 
exercendo decisivo papel no desenvolvimento de normas relacionadas às suas áreas temáticas, tais como as pesquisas envolvendo seres humanos e os conflitos éticos relacionados à assistência em saúde.

Observa-se que, aos poucos, a temática do consentimento livre e esclarecido vem sendo inserida na legislação brasileira pertinente. É o que se observa, pois, da Lei n. 9.263/96 (26), que trata do planejamento familiar; da Lei n. 9.434/97(27), que dispõe sobre o transplante de órgãos; e da Resolução n. 1.358/92 (28), do Conselho Federal de Medicina, que estabelece "normas éticas para a utilização de técnicas de reprodução assistida".

Ressalte-se que o Estado de São Paulo apresenta legislação pioneira que versa sobre os direitos dos usuários dos serviços e das ações de saúde (Lei Estadual n. 10.241, de 1999). Referida lei estabelece como direito do usuário "consentir ou recusar, de forma livre, voluntária e esclarecida, com adequada informação, procedimentos diagnósticos ou terapêuticos a serem nele realizados".

Ainda no que se refere à legislação, observa-se que o Novo Código Civil Brasileiro (Lei n. 10.406, de 10 de janeiro de 2002) introduziu no inédito capítulo 'Dos direitos da personalidade', o artigo 15, segundo o qual: "Ninguém pode ser constrangido a submeter-se, com risco de vida, a tratamento médico ou a intervenção cirúrgica”.

A despeito de não tratar explicitamente sobre o consentimento livre e esclarecido, referido dispositivo de Lei é entendido por Lima(29) como a positivação do consentimento livre e esclarecido no Brasil. Ressalte-se, entretanto, que a redação de tal artigo é considerada deficiente, pois, nos dizeres de Sztajn( ${ }^{(30)}$, "interpretação a contrario sensu (...) evidencia que qualquer pessoa pode ser constrangida a submeter-se a tratamento médico ou intervenção cirúrgica, desde que não haja risco de vida".

(26) Art. 10, § 1ํ: "É condição para que se realize a esterilização o registro de expressa manifestação da vontade em documento escrito e firmado, após a informação a respeito dos riscos da cirurgia, possíveis efeitos colaterais, dificuldades de sua reversão e opções de contracepção reversíveis existentes."

(27) Art. 10, caput - "O transplante ou enxerto só se fará com o consentimento expresso do receptor, assim inscrito em lista única de espera, após aconselhamento sobre a excepcionalidade e os riscos do procedimento."

(28) 3 - "O consentimento informado será obrigatório e extensivo aos pacientes inférteis e doadores. Os aspectos médicos envolvendo todas as circunstâncias da aplicação de uma técnica de RA serão detalhadamente expostos, assim como os resultados já obtidos naquela unidade de tratamento com a técnica proposta. As informações devem também atingir dados de caráter biológico, jurídico, ético e econômico. O documento de consentimento informado será em formulário especial, e estará completo com a concordância, por escrito, da paciente ou do casal infértil."

(29) LIMA, J. L. B. de O consentimento informado e seu amparo constitucional. 2005. 305 p. Dissertação (Mestrado em Direito) - Faculdade de Direito, Pontifícia Universidade Católica de São Paulo, São Paulo, 2005.

(30) SZTAJN, R. Consentimento informado e o projeto de Código Civil. Revista de Direito Mercantil Industrial, Econômico e Financeiro, São Paulo, n. 109, p. 96, jan./mar. 1998. 
Nesse sentido, Borges ${ }^{(31)}$ observa que:

Infere-se, do art. 15 do Código Civil, que a pessoa pode opor-se ao tratamento médico (incluindo-se aí a intervenção cirúrgica), sobretudo se tal tratamento apresentar risco à sua integridade física ou à vida, embora a pessoa possa opor-se inclusive se não houver esse risco.

\section{A JURISPRUDÊNCIA DOS TRIBUNAIS BRASILEIROS ${ }^{(32)}$}

No que se refere aos processos judiciais envolvendo a atividade médica no Brasil, verifica-se o seu aumento progressivo, intensificado a partir da década de 1980 (Fortes) $^{(33)}$. Assim, entre os anos 1980 e 1989, foram localizadas 82 (oitenta e duas) decisões relacionadas à responsabilidade médica nos tribunais brasileiros, contra as 44 (quarenta e quatro) da década anterior.

Já em estudo realizado entre 2000 e 2004 pelo Conselho Regional de Medicina do Estado de São Paulo (Cremesp), em parceria com o Instituto de Defesa do Consumidor, foram localizadas, somente na Justiça estadual paulista e nos tribunais superiores, 376 (trezentas e setenta e seis) decisões judiciais envolvendo a responsabilidade médica(34).

Esse acentuado aumento do número de processos judiciais relacionados à atividade médica também se reflete nos números de denúncias realizadas por pacientes junto ao Conselho Regional de Medicina do Estado de São Paulo. Segundo dados do Cremesp, o número de denúncias contra médicos recebidas pelo órgão aumentou cerca de $150 \%$ entre os anos de 1995 e $2005^{(35)}$.

Tal situação pode ser entendida como uma consequência da crise pela qual passa hoje a relação médico-paciente no país:

(31) BORGES, R. C. B. Disponibilidade dos direitos de personalidade e autonomia privada. São Paulo: Saraiva, 2005. p. 202.

(32) Os resultados apresentados são fruto de levantamento jurisprudencial realizado entre os anos de 2000 e 2006 nos seguintes tribunais: Supremo Tribunal Federal, Superior Tribunal de Justiça e tribunais dos Estados de São Paulo, Rio de Janeiro, Minas Gerais e Rio Grande do Sul, conforme GUZ, G. O consentimento livre e esclarecido na prática médica: um estudo da jurisprudência dos tribunais brasileiros. 2007. 147 p. Dissertação (Mestrado em Saúde Pública), Faculdade de Saúde Pública, Universidade de São Paulo, São Paulo, 2007.

(33) FORTES, P.A.C. A responsabilidade médica nos tribunais. 1994. 199 p. Tese (Doutorado em Saúde Pública) - Faculdade de Saúde Pública, Universidade de São Paulo, São Paulo, 1994.

(34) CREMESP — CONSELHO REGIONAL DE MEDICINA DO ESTADO DE SÃO PAULO. O médico e a justiça: um estudo sobre ações judiciais relacionadas ao exercício profissional da medicina. São Paulo, 2006.

(35) DENÚNCIAS e processos contra médicos no Conselho Regional de Medicina do Estado de São Paulo. CREMESP (Conselho Regional de Medicina do Estado de São Paulo), 2006. Disponível em: <http://www.cremesp.org.br/?siteAcao=Salalmprensa\&id=131>. Acesso em: 05 fev. 2007. 
As circunstâncias hoje estão mudadas. As relações sociais massificaram-se, distanciando o médico do seu paciente. A própria denominação dos sujeitos da relação foi alterada, passando para usuário e prestador de serviços, tudo visto sob a ótica de uma sociedade de consumo, cada vez mais consciente de seus direitos, reais ou fictícios, e mais exigente quanto aos resultados. ${ }^{(36)}$

Assim, se de um lado a medicina atingiu um fantástico desenvolvimento tecnológico antes sequer imaginado, possibilitando o aumento da expectativa e da qualidade da vida humana, de outro, paradoxalmente, o que se vê é que a relação médico-paciente nunca esteve tão doente no Brasil.

Referida situação se aproxima em muita daquela verificada nos tribunais estadunidenses a partir da década de 1950, antes mencionada, e que, inclusive, propiciou todo o desenvolvimento do que ficou conhecido como a doutrina do consentimento informado.

Cabe salientar que, diferentemente do que ocorre na tradição anglosaxônica, em que a jurisprudência constitui a principal expressão do direito, no Brasil, adotou-se a tradição jurídica romanística, na qual as leis adquirem uma preeminência ${ }^{(37)}$ (Ferraz Junior, 2003).

Entretanto, forçoso é observar-se que em nosso ordenamento jurídico:

A jurisprudência, de um modo ou de outro, acaba impondo ao legislador uma nova visão dos institutos jurídicos, alterando-os, às vezes integralmente, forçando a expedição de leis que consagrem sua orientação. É indubitável que constitui, além de uma importantíssima fonte de normas jurídicas gerais, uma fonte subsidiária de informação, no sentido de que atualiza o entendimento da lei, dando-Ihe uma interpretação atual que atenda aos reclamos das necessidades do momento do julgamento e do preenchimento de lacunas. ${ }^{(38)}$

No mesmo sentido, afirma Sabino(39) que "o estudo da pluralidade de entendimentos existentes nos tribunais pode revelar os valores que estão sendo cada vez mais tutelados e os mecanismos de proteção cada vez mais aceitos, ainda que contrários a uma concepção mais ortodoxa".

\section{Novos rumos da responsabilidade civil médica nos tribunais}

A responsabilidade civil médica pode ser motivada por faltas técnicas ou por faltas contra o humanismo médico ${ }^{(40)}$. As faltas técnicas "são aquelas

(36) AGUIAR JR, R.R. Responsabilidade civil do médico. In: TEIXEIRA, S. F. (Coord.). Direito e medicina. Belo Horizonte: Del Rey, 2000. p. 136.

(37) FERRAZ JUNIOR, T. S. Estudos de filosofia do direito: reflexões sobre o poder, a liberdade, a justiça e o direito. São Paulo: Atlas, 2002.

(38) DINIZ, M. H. Compêndio de introdução à ciência do direito. 16. ed. São Paulo: Saraiva, 2004. p. 299. (39) SABINO, P. A. L. Notas acerca do valor metodológico do estudo jurisprudencial. Jus Navigandi: Teresina, ano 8, n. 352, 24 jun. 2004. Disponível em: <http://jus2.uol.com.br/doutrina/texto.asp?id=5382>. Acesso em: 02 dez. 2005.

(40) FORTES, P.A.C. A responsabilidade médica nos tribunais, cit., p. 15. 
que não seriam cometidas por um profissional competente e diligente agindo nas mesmas circunstâncias, observando as regras da ciência e da arte de sua profissão". Já as faltas contra o humanismo médico correspondem àquelas "decorrentes de atos ou procedimentos que ferem direitos individuais fundamentais dos cidadãos enquanto usuários dos serviços de saúde"(41).

As faltas contra o consentimento livre e esclarecido são, pois, classificadas como falta contra o humanismo médico ${ }^{(42)}$ (Fortes, 1998).

No Direito brasileiro, a má atuação profissional do médico tradicionalmente é associada à ideia de falta técnica. Assim, o erro médico constitui expressão frequentemente utilizada para se referir à falta técnica.

Entretanto, as decisões atualmente verificadas denotam nova tendência dos tribunais brasileiros: o reconhecimento da responsabilidade civil do médico em função da ausência (ou deficiência) de informação prestada ao paciente e/ou da falta de obtenção de seu consentimento, ainda que o profissional não tenha cometido qualquer falta técnica:

O laudo pericial informa que, do ponto de vista técnico, as cirurgias realizadas pelo réu estão corretas. (...) Houve uma redução da acuidade visual do paciente, que pode ter decorrido de complicações inerentes à técnica cirúrgica, ao que se acrescenta a necessidade de saber se o réu obteve do paciente o necessário consentimento à realização da intervenção, em decorrência do devido esclarecimento prestado sobre suas consequências, não assegurada a obtenção de sucesso. (...) A responsabilidade do médico decorre da falta de cientificação adequada ao paciente, caracterizando a culpa no aspecto negligência. (TJ-SP, Apelação Cível n. 136.164.4/0-00, Rel. Des. Marcus Andrade, $5^{\text {a }}$ Câmara de Direito Privado, 28.08.2003)

Observa-se que os próprios tribunais reconhecem tratar-se de nova tendência sobre a responsabilidade civil médica:

Aliás, atualmente, encontra-se em voga a discussão sobre a inobservância do dever de informação como modalidade de responsabilização médica. Modernamente, além dos deveres de cuidado e sigilo, vem se exigindo da classe médica que oriente e informe objetivamente os pacientes a respeito de toda a terapêutica ou cirurgia indicada, bem como, sobre os riscos e prováveis resultados. Ainda, o médico também precisa obter indispensavelmente o consentimento do próprio paciente ou de seu responsável na hipótese de procedimento arriscado.

(TJ-RS, Apelação Cível n. 70009997982, Relator Desa ${ }^{a}$ Íris Helena Medeiros Nogueira, 9ª Câmara Cível, j. 30.05.2005)

(41) FORTES, P.A.C. A responsabilidade médica nos tribunais, cit., p. 15.

(42) Id. Ética e saúde, cit. 
Tal tendência deixa patente o estabelecimento de dois deveres ao profissional: o de obter o consentimento do paciente e o de informá-lo.

Cumpre ressaltar que foram justamente esses os deveres imputados aos médicos pelos tribunais estadunidenses como decorrência do desenvolvimento do 'consentimento informado' no contexto judicial: em um primeiro momento, o dever de obter o consentimento ou a autorização do paciente e, posteriormente, o dever de informar ${ }^{(43)}$.

\section{O dever de informar}

\subsection{A aplicação do Código de Defesa do Consumidor}

Nas decisões judiciais pertinentes à responsabilidade civil médica, o dever de informar é observado com muito mais frequência do que o questionamento sobre o dever de obter o consentimento do paciente.

De acordo com Fabian (44), "nos anos noventa iniciou-se uma sensibilização jurídica para com os deveres de informar. Um fator para o interesse crescente foi a entrada em vigor do Código de Defesa do Consumidor em $1990^{(45)}$, que postula expressamente vários deveres de informar com importância prática e dogmática".

Observa-se, atualmente, a tendência jurídica brasileira de reconhecer a relação médico-paciente como uma relação de consumo e, consequentemente, de aplicar o Código de Defesa do Consumidor aos processos envolvendo a responsabilidade médica - o que, inclusive, pôde ser verificado em diversas decisões obtidas, como se exemplifica a seguir:

A relação médico/paciente, por caracterizar uma prestação de serviço, está subordinada às normas do Código de Defesa do Consumidor, estando o profissional obrigado a informar ao paciente os riscos e consequências possíveis (...). (TA-MG, Apelação Cível n. 2.0000.00.400722-9/000, Relator Juiz Guilherme Luciano Baeta Nunes, $7^{\mathrm{a}}$ Câmara Cível, j. 11.03.2004)

Verifica-se, pois, que a entrada em vigor do Código de Defesa do Consumidor no ano de 1991, e sua consequente aplicação à atividade médica, impulsionaram o questionamento sobre o dever médico de informar pelos tribunais brasileiros.

(43) APPELBAUM, P.; LIDZ, C.W.; MEISEL, A. op. cit.

(44) FABIAN, C. O dever de informar no direito civil. São Paulo: Ed. Revista dos Tribunais, 2002. p. 39.

(45) O Código de Defesa do Consumidor - Lei n. 8.078 - foi publicado em 11 de setembro de 1990 , mas só entrou em vigor em 11 de março de 1991, ou seja, 180 dias após a sua publicação, como estabelecido em seu artigo 118. 


\section{2. $O$ conteúdo e a extensão da informação}

Os critérios ou modelos de revelação da informação estabelecem as balizas do dever de informar do médico, tendo sido criados pelos tribunais estadunidenses em processos em que os pacientes alegavam a violação de seu direito à informação pelos médicos. São utilizados, pois, para se avaliar, no caso concreto, se foi revelada a informação considerada 'adequada'(46).

Três foram os critérios estabelecidos pela jurisprudência estadunidense: o da prática profissional, o objetivo e o subjetivo.

O critério da prática profissional padroniza as informações a serem reveladas, que, por sua vez, são determinadas pelo costume da profissão.

O critério objetivo igualmente padroniza as informações a serem transmitidas ao paciente. Entretanto, a determinação da necessária informação baseia-se não naquilo que outro profissional informaria em condições similares, mas no que uma hipotética pessoa sensata decidiria se estivesse adequadamente informada. Corresponde, pois, ao modelo de revelação de informações adotado pelo Código de Defesa do Consumidor.

O critério subjetivo implica o abandono de fórmulas padronizadas da informação a ser revelada, de tal sorte que deve a mesma ser adequada às necessidades específicas do paciente concreto.

A adoção do critério objetivo ou da 'pessoa sensata' é largamente verificado na jurisprudência dos tribunais brasileiros, especialmente em função da aplicação do Código de Defesa do Consumidor à relação médico-paciente:

Conforme esclarece MIGUEL KFOURI NETO (ob. cit., p. 303), 'deve-se demonstrar que a pessoa comum teria recusado o tratamento, caso fosse convenientemente informada. Nega-se a indenização se, com as mesmas informações e nas mesmas circunstâncias, outra pessoa, razoavelmente, aceitasse se submeter a terapia'.

(...)

Como não há nos autos demonstração clara no sentido de que o autor ou uma pessoa média em seu lugar deixaria de aceitar ou se submeter ao tratamento indicado, incluída a cirurgia, é razoável entender que não tinha ele outra alternativa. (TJ-RS, Apelação Cível n. 70006796700, Relatora Des. Ana Lúcia Carvalho Pinto Vieira, 10ª Câmara Cível, j. 27.11.2003)

Rechaçando a adoção de tal critério, Sotto(47) observa que:

Enquanto que na relação de consumo propriamente dita o destinatário da informação é o consumidor "médio" ou "típico", consistente num tipo ideal,

(46) SIEGLER, M.; COLLINS, M. E.; CRONIN, D. C. Special challenges to the informed consent doctrine in the United States. The Journal of Clinical Ethics, v. 15, n. 1, p. 38-47, spring 2004.

(47) SOTTO, D. O dever de informar do médico e o consentimento informado do paciente. Medidas preventivas à responsabilização pela falta ou deficiência de informação. Jus Navigandi, Teresina, ano 8, n. 178, 31 dez. 2003. Disponível em: <http://www1.jus.com.br/doutrina/texto.asp?id=4635>. Acesso em: 12 dez. 2004. 
construído a partir do interesse coletivo de todos os destinatários, na relação médico-paciente o destinatário da informação é o paciente em concreto, um indivíduo dotado de características únicas e inserido num contexto social, familiar e pessoal absolutamente peculiar.

De outra sorte, não se verificou em qualquer das decisões obtidas a adoção do critério subjetivo de informação.

O critério subjetivo é eticamente ideal(48), pois, à medida que reconhece as necessidades de informação específicas de cada pessoa, possibilita o respeito à autonomia do paciente na tomada de decisões sobre a própria saúde. Além disso, constitui o critério que mais se aproxima da abordagem da 'informação' enquanto um 'processo de troca de informações' entre médico e paciente.

Isso porque:

Requer que (o profissional) descubra, baseando-se no conhecimento e na arte de sua prática, e observando as condições emocionais do paciente perante sua doença ou agravo à sua saúde, assim como fatores sociais e culturais a ele relacionados, o que realmente cada indivíduo gostaria de conhecer e o quanto gostaria de participar das decisões ${ }^{(49)}$.

Cabe ressaltar que a legislação consumerista não especifica quais são as informações necessárias à compreensão do 'homem médio' no contexto médico.

No que se refere à natureza das informações a serem reveladas, Kuczewski e Meisel(50) ressaltam que:

O foco deve estar mais nas opções terapêuticas e menos nos riscos de uma única opção. (...) O conhecimento sobre as opções, entretanto, não tem significado a menos que o indivíduo saiba as consequências de escolher cada uma das opções. O risco do tratamento é uma face da informação, mas outras, tais como informações sobre resultados prováveis, incluindose a mortalidade, a morbidade, e a funcionalidade, também precisam ser discutidas.

Entretanto, observa-se que a jurisprudência brasileira verificada refere-se ao dever médico de informar especificamente sobre os riscos. Tal fato pode ser justificado pela própria natureza da ação de responsabilidade civil médica, em que se está discutindo um risco inerente a determinado procedimento médico que, no caso concreto, acabou materializando-se:

A correta informação quanto aos riscos do serviço teria possibilitado à Apelada que escolhesse submeter-se à cirurgia ou a tratamento clínico, que

(48) SIEGLER, M.; COLLINS, M. E.; CRONIN, D. C. op. cit., p. 38-47.

(49) FORTES, P.A.C. Ética e saúde, cit.

(50) KUCZEWSKI, M.; MEISEL, A. op. cit., p. 2. 
o próprio Apelado refere ser possível. (TJ-RJ, Apelação Cível n. 2004.001.03392, Relator Des. Luiz Fernando Ribeiro de Carvalho, 3ª Câmara Cível, j. 28.09.2004)

No que se refere à quantidade de informações - ou, especificamente, a quais riscos devem ser informados -, ressaltam Beauchamp e Childress ${ }^{\left({ }^{15}\right)}$ que "há muitas controvérsias em torno de quanto deve ser revelado acerca dos riscos de um procedimento (...)".

Kfouri Neto(52) observa que "em geral, admite-se que o médico deva informar os riscos mais comuns, pena de se transformar a consulta médica em verdadeiro curso de medicina. Assim, não haveria necessidade de relatar riscos excepcionais, anormais e estranhos".

Prevalece entre os julgados encontrados o entendimento do amplo dever de informar, no sentido de que deve ser informado ao paciente todo e qualquer tipo de risco. Entretanto, foram verificadas decisões que privilegiam a informação sobre os riscos mais graves e, de outro lado, decisões que estabelecem o dever de informar os riscos mais frequentes:

(...) As exigências do princípio do consentimento informado devem ser atendidas com maior zelo na medida em que aumenta o risco, ou o dano, ou diminui a possibilidade de êxito. Nas circunstâncias dos autos, assim como admitido pelo Tribunal e acima parcialmente descrito, o dever de informação antes e depois da cirurgia não foi cumprido. (REsp n. 436.827/SP, Relator Ministro Ruy Rosado de Aguiar, 4⿳a Turma, j. 01.10.2002)

Ademais, é obrigação do médico informar o paciente quanto à conveniência da intervenção cirúrgica e suas possíveis consequências, como por exemplo, os riscos que podem advir de uma anestesia geral, bem como a possibilidade de êxito ou de agravamento do quadro. Mesmo os acidentes mais raros, as sequelas mais infrequentes, devem ser relatados, sob pena de responder pelas possíveis lesões ocorridas. (TA-MG, Apelação Cível n. 2.0000.00.453379-5/000, Relatora Juíza Heloísa Combat, 6ª Câmara Cível, j. 16.09.2004.

(...) Informar o paciente do tratamento não quer dizer explicar todos os detalhes particulares que estão implicitamente conexos ou vinculados com um tratamento realizado segundo as lex artis ou que são inerentes à sua execução, bastando que o paciente seja informado sobre o tratamento que o médico pretende realizar e sobre suas consequências. (TJ-RS, Apelação Cível n. 70011788148, Relator Des. Odone Sanguiné, 9aํ Câmara Cível, j. 24.08.2005, grifos no original)

(51) BEAUCHAMP, T. L.; CHILDRESS, J. F. op. cit., p. 168.

(52) KFOURI NETO, M. Culpa médica e ônus da prova. São Paulo: Ed. Revista dos Tribunais, 2002. p. 301. 
De acordo com Siegler e col. ${ }^{(53)}$, as exigências quanto ao conteúdo da informação variam de acordo com a situação clínica, de modo que a emergência requer exigências menores de informação. De outro lado, tais exigências são mais rigorosas em se tratando de procedimentos eletivos.

Verifica-se tal entendimento na jurisprudência brasileira, de modo que a exigência quanto ao conteúdo da informação a ser prestada mostra-se com muito mais rigor em procedimentos eletivos, principalmente naqueles considerados estéticos - que, ressalta-se, concentram a maior parte dos julgados obtidos relacionados ao 'dever de informar':

É que, na cirurgia estética, o paciente visa a uma melhora na sua aparência física e o médico deve informar-se de todas as condições do mesmo. Se, eventualmente, faltam-Ihe informações precisas, ou deixa de bem esclarecero cliente sobre o risco, haverá responsabilidade. É rigoroso o cumprimento do dever de informação e cuidado na execução do trabalho do médico cirurgião plástico. (TJ-RS, Apelação Cível n. 70004518759, Relatora Des. Rejane Maria Dias de Castro Bins, 9ª Câmara Cível, j. 11.04.2003)

\subsection{Informação x esclarecimento}

Como se pôde verificar, o dever de informar delineado pelos tribunais brasileiros está, via de regra, focado na transmissão de informações ao paciente pelo médico, e não na comunicação e na troca de informações entre ambos.

Observa-se, inclusive, a identificação do cumprimento do dever de informar, enquanto uma transmissão de informações, com a própria obtenção do consentimento livre e esclarecido:

(...) Todas as informações pertinentes ao exame e as reações possíveis de ocorrerem foram prestadas à paciente. $O$ consentimento informado foi observado com clareza. (TJ-RJ, Apelação Cível n. 2005.001.29690, Relator Des. Antonio Saldanha Palheiro, 5ª Câmara Cível, j. 11.10.2005)

Já em decisão proferida pelo Superior Tribunal de Justiça, que constitui uma das primeiras proferidas pela referida Corte sobre a temática do consentimento livre e esclarecido, verifica-se um princípio de diferenciação entre a transmissão de informações e o esclarecimento propriamente dito:

Do ponto de vista doutrinário e legal, o r. acórdão apenas acentuou o dever ético do médico de informar o paciente sobre as consequências da cirurgia, $o$

(53) SIEGLER, M.; COLLINS, M. E.; CRONIN, D. C. op. cit., p. 39. 
que não se confunde com a singela comunicação de que o ato operatório seria difícil e demorado, nada esclarecendo sobre a conveniência da intervenção cirúrgica, resultados, expectativas e possibilidades de êxito ou de agravamento do quadro. (REsp n. 436.827/SP, Relator Ministro Ruy Rosado de Aguiar, 4aㅗ Turma, j. 01.10.2002)

Beauchamp e Faden ${ }^{(54)}$ ressaltam que, nos Estados Unidos, "com a evolução da ideia de consentimento informado, a discussão sobre diretrizes apropriadas passou do limitado foco na obrigação do médico ou do pesquisador de fornecer informações para a qualidade da compreensão das informações pelo paciente ou sujeito de pesquisa e seu direito de autorizar ou recusar uma intervenção biomédica".

Da mesma forma, Etchells e col. ${ }^{(55)}$ ressaltam que "a revelação de informações no contexto do consentimento do paciente refere-se tanto ao fornecimento de tais informações pelo médico quanto à compreensão das mesmas pelo paciente. Ambos os elementos são necessários ao consentimento válido".

De outra sorte, a preocupação com a compreensão das informações pelo paciente só foi explicitada em relação ao termo de consentimento, como se verificará a seguir.

\section{O termo de consentimento livre e esclarecido}

No Brasil, a utilização obrigatória do termo de consentimento livre e esclarecido foi instituída pela Resolução n. 196/96, do Conselho Nacional de Saúde ${ }^{(56)}$, especificamente para as pesquisas envolvendo seres humanos.

Já no que se refere à prática de assistência em saúde, não se verifica uma regra geral de obtenção obrigatória do termo de consentimento livre e esclarecido. Dessa forma, apenas em situações específicas, como a do planejamento familiar ${ }^{(57)}$, a da utilização de técnicas de reprodução

(54) BEAUCHAMP T. L.; FADEN, R. R. op. cit., p. 1271.

(55) ETCHELLS, E. et al. Disclosure. In: SINGER, P.A. (Ed.). Bioethics at the bedside. Ottawa: Canadian Medical Association, 1999. p. 10.

(56) MINISTÉRIO DA SAÚDE. Conselho Nacional de Saúde. Resolução n. 196, de 10 de outubro de 1996. Aprova diretrizes e normas regulamentadoras de pesquisas envolvendo seres humanos. Brasília: Disponível em <http://conselho.saude.gov.br/comissao/conep/resolucao.html>. Acesso em: 14 mar. 2006.

(57) Lei n. 9.263/96, artigo 10: “(...) § 1ํ É condição para que se realize a esterilização o registro de expressa manifestação da vontade em documento escrito e firmado, após a informação a respeito dos riscos da cirurgia, possíveis efeitos colaterais, dificuldades de sua reversão e opções de contracepção reversíveis existentes. (...) $\S 5^{\circ} \mathrm{Na}$ vigência de sociedade conjugal, a esterilização depende do consentimento expresso de ambos os cônjuges." 
assistida ${ }^{(58)}$ e a da realização de cirurgias de lipoaspiração(59), é tida como obrigatória a obtenção do referido termo.

Entretanto, já são diversos os sítios eletrônicos que disponibilizam aos médicos modelos de termos de consentimento a serem utilizados em sua atividade profissional.

O caráter de prova documental que se pretende dar a tais documentos é evidente, posto que apresentam, inclusive, campo a ser preenchido por testemunhas.

Tais dados refletem o crescimento da denominada 'medicina defensiva', originária dos Estados Unidos e que, baseada no aumento do número de processos envolvendo a responsabilidade médica, "sugere que o médico veja em todo paciente um potencial inimigo que pode processá-lo a qualquer momento"(60), de modo que o médico deve adotar determinadas medidas em sua prática profissional, visando a sua defesa em eventual situação de processo judicial.

Como antes ressaltado, foi no contexto da prática defensiva que o 'termo de consentimento informado' passou a ser elaborado pelos médicos estadunidenses para fins de documentação e posterior comprovação do cumprimento dos deveres de obter o consentimento do paciente e de informá-lo.

No Brasil, os termos de consentimento livre e esclarecido ainda não são apresentados com frequência, pelos médicos, como prova documental do cumprimento de tais deveres em processos judiciais.

Entretanto, quando o termo de consentimento está presente no processo judicial, verificamos decisões em que os tribunais manifestam-se no sentido de aceitá-lo como prova do cumprimento do dever de informar que, como antes visto, constitui o dever frequentemente verificado nas decisões judiciais obtidas:

Ocorre que o recorrente [paciente] nada comprovou sobre a conduta culposa dos réus.

Ao contrário, estes é que revelaram que o autor firmou documento, declarandose ciente de que a vasectomia não era infalível (fl. 61). (TJ-SP, Apelação Cível n. 94.019-4/4, Relator Des. Gildo dos Santos, 1르 Câmara de Direito Privado, j. 09.05.2000)

(58) Resolução n. 1.358/92, do Conselho Federal de Medicina: "3 - O consentimento informado será obrigatório e extensivo aos pacientes inférteis e doadores. Os aspectos médicos envolvendo todas as circunstâncias da aplicação de uma técnica de RA serão detalhadamente expostos, assim como os resultados já obtidos naquela unidade de tratamento com a técnica proposta. As informações devem também atingir dados de caráter biológico, jurídico, ético e econômico. O documento de consentimento informado será em formulário especial, e estará completo com a concordância, por escrito, da paciente ou do casal infértil."

(59) Resolução n. 1.711/03, do Conselho Federal de Medicina, artigo 6으, § 2o: "O paciente ou seu responsável legal deve ter prévio esclarecimento sobre o tipo de anestesia indicado, e manifestar seu consentimento."

(60) EM DEFESA de quem? Ser médico. Revista do Conselho Regional de Medicina do Estado de São Paulo, São Paulo, n. 21, p. 25, out./dez. 2002. 
Kuczewski e Meisel(61) observam que, nos Estados Unidos, os termos de consentimento são utilizados com frequência tanto no âmbito da pesquisa quanto da assistência, pois vários administradores hospitalares, médicos e advogados vêem tais termos como forma de proteção contra a responsabilização médica - apesar de, no entendimento dos autores, os termos propiciarem pouca proteção. Assim, salientam os mesmos que, se a informação apresentada em tais termos for adequada à tomada de decisão do paciente, provavelmente o 'termo' será útil na defesa do profissional em um processo envolvendo a responsabilidade médica.

Nesse sentido, foram verificadas decisões que se ocuparam da forma e do conteúdo dos termos de consentimento apresentados, deixando de aceitá-los por serem considerados inadequados à comprovação do devido cumprimento do dever de informar:

Contudo, o referido documento, onde consta o consentimento dado pela recorrente, trata-se de formulário padrão, que não contém informações detalhadas, claras e precisas a respeito da cirurgia sob anestesia geral a que seria submetida a criança.

Nesse passo, os ensinamentos de Miguel Kfouri Neto:

'A prova do consentimento pode acarretar dificuldades. Ao juiz é dada ampla liberdade de apreciá-la - e grande latitude para decidir. A informação prestada pelo médico deve ser inteligível e leal. Tanto a informação quanto o consentimento devem ser escritos, individualizados e testemunhados. A adoção dos formulários é difícil, dadas as peculiaridades de cada caso. De qualquer modo, não podem suscitar a menor dúvida.' (Responsabilidade Civil do Médico - RT: 2003, p. 167/168). Grifos nossos." (TA-MG, Apelação Cível n. 2.0000.00.413571-7/000, Relatora Juíza Heloísa Combat, 6ª Câmara Cível, j. 04.03.2004)

Cabe salientar que a preocupação dos tribunais com a questão da 'compreensão' está relacionada ao fato de a padronização das informações em um formulário aproximar-se do típico contrato de adesão consumerista, cuja clareza e legibilidade são exigidas pelo Código de Defesa do Consumidor ${ }^{(62)}$.

Observa-se, inclusive, que há entendimento doutrinário, no sentido de definir o 'consentimento livre e esclarecido' como um contrato de adesão, deixando, assim, de diferenciá-lo do termo de consentimento livre e esclarecido:

(61) KUCZEWSKI, M.; MEISEL, A. op. cit., p. 2.

(62) Lei n. 8.078/90, artigo 54: "Contrato de adesão é aquele cujas cláusulas tenham sido aprovadas pela autoridade competente ou estabelecidas unilateralmente pelo fornecedor de produtos ou serviços, sem que o consumidor possa discutir ou modificar substancialmente seu conteúdo. (...) § 3 - - Os contratos de adesão escritos serão redigidos em termos claros e com caracteres ostensivos e legíveis, de modo a facilitar sua compreensão pelo consumidor." 
Como ensina Ruy Rosado, em matéria de serviço médico e de saúde, é muito importante a figura do consentimento informado e do acesso às informações médicas. Trata-se de contratos de adesão e condições gerais contratuais (formulários de consentimento e internação avulsos), estando o paciente e sua família (consumidores) em situação de extrema vulnerabilidade. ${ }^{(63)}$

Cabe ressaltar, entretanto, que existem profundas diferenças entre 0 'consentimento livre e esclarecido' e o 'termo de consentimento livre e esclarecido'. Isso porque:

(...) o consentimento é um processo e não uma forma. O consentimento tem que ser perspectivado como um diálogo entre o doente e o médico, em que ambas as partes trocam informações e se interrogam reciprocamente: diálogo que há de culminar na concordância ou anuência do doente à realização de um certo tratamento ou de uma certa intervenção. (...)

É inconcebível que um qualquer formulário de consentimento assinado pelo doente possa sobrepor-se ou sequer substituir-se à recíproca troca de informações. ${ }^{(64)}$.

Ali ${ }^{(65)}$ observa que, para que o termo de consentimento livre e esclarecido seja verdadeiramente eficaz, deve ser utilizado como um instrumento para facilitar a tomada de decisão, e não como um obstáculo burocrático a ser transpassado.

De se observar ainda que, além da aceitação do termo de consentimento livre e esclarecido como prova documental, verifica-se ainda que, em alguns julgados, o termo de consentimento livre e esclarecido é até mesmo exigido.

O apelado-médico, em seu depoimento pessoal de f. 308, diz que não exige consentimento escrito do paciente para realização da cirurgia.

Portanto, os apelados não fizeram prova de terem prestado informações concretas ao paciente e/ou a seus familiares, sobre o alto risco da cirurgia. (TA-MG, Apelação Cível n. 2.0000.00.400722-9/000, Relator Juiz Guilherme Luciano Baeta Nunes, $7^{\text {ạ }}$ Câmara Cível, j. 11.03.2004)

Competiria, que o réu o comunicasse, por escrito, dos riscos da cirurgia e o fizesse assinar esse documento, cientificando-o, assim de que o resultado pretendido poderia não ser alcançado. (TJ-SP, Apelação Cível n. 136.164.4/000, Rel. Des. Marcus Andrade, 5르 Câmara de Direito Privado, 28.08.2003)

A esse respeito, Ruy Rosado de Aguiar Jr., ex-ministro do Superior Tribunal de Justiça e Relator das primeiras decisões proferidas naquela

(63) MARQUES, C.L. A responsabilidade dos médicos e do hospital por falha no dever de informar ao consumidor. Revista dos Tribunais, São Paulo, ano 93, v. 827, p. 20, set. 2004.

(64) DIAS apud KFOURI NETO, M. op. cit., p. 313.

(65) ALI, V. op. cit. 
Corte a respeito do consentimento livre e esclarecido(66), assim já se manifestou (67): "A conclusão sobre o âmbito da informação e da existência do consentimento deve ser extraída, pelo juiz, do conjunto dos fatos provados, e mais precavido será o médico que obtiver declaração escrita do paciente ou de seu representante".

De se ressaltar que, em alguns julgados, verificou-se, inclusive, a manifestação dos próprios peritos médicos, no sentido de exigirem o termo de consentimento livre esclarecido:

Por outro lado, não consta que o réu tivesse expressamente alertado a paciente sobre a possibilidade de resultado não desejado, e que tivesse colhido uma autorização para, mesmo assim, realizar a cirurgia.

O próprio perito registrou em suas 'considerações' (f. 5):

7. Não encontramos nos Autos qualquer documento de 'Adesão a Tratamento Cirúrgico' que esclarecesse à Autora a relação biológica de custo/benefício de uma Mamoplastia (sic) Redutora (...).

8. Este documento deveria ter sido redigido pelo médico e assinado pelo cliente.

Parece que esta normatização não chegou ainda nas cidades de menor porte.

(TA-MG, Apelação Cível n. 360.091-5, Relator Juiz Guilherme Luciano Baeta Nunes, 7 ${ }^{a}$ Câmara Cível, j. 27.06.2002)

O cenário apresentado em tais decisões judiciais revela-se, pois, propício ao entendimento de que a adoção do termo de consentimento livre e esclarecido, pelo médico, é eficaz para a finalidade de comprovar o cumprimento dos deveres de informar e/ou de obter o consentimento do paciente.

Cabe observar ainda que algumas decisões obtidas focam no prontuário médico a prova documental do cumprimento dos deveres de obter o consentimento do paciente e de informar, e não no termo de consentimento livre e esclarecido:

Portanto, que se estabeleça como premissa do julgamento de que, embora não exista contrato cientificando que as partes combinaram uma cirurgia plástica estética, não há, igualmente, prontuário médico revelador do consentimento do paciente para que seu colo e abdômen sofresse incisão agressiva para outro fim que não a redução do volume das mamas e eliminação de cicatrizes de cesariana. (TJ-SP, Apelação Cível n. 192.514-4/8-00, Relator Des. Ênio Zuliani, 4ª Câmara de Direito Privado, j. 28.07.2005)

Kuczewski e Meisel|(68) observam que, atualmente, nos Estados Unidos, "instituições mais progressistas aboliram os termos de consentimento

(66) Nas referidas decisões (REsp n. 436.827 e 467.878) , foi utilizada a expressão 'consentimento informado', e não 'consentimento livre e esclarecido'.

(67) AGUIAR JR, R. R. op. cit., p. 142.

(68) KUCZEWSKI, M.; MEISEL, A. op. cit., p. 2. 
padronizados, de tal sorte que requerem aos médicos que documentem o conteúdo de suas conversações com os pacientes nos respectivos prontuários médicos".

\section{CONSIDERAÇÕES FINAIS}

O questionamento sobre o direito do paciente à informação, impulsionado pela aplicação do Código de Defesa do Consumidor, revela-se como 'porta de entrada' para a discussão sobre o consentimento livre e esclarecido nos tribunais brasileiros.

Dessa forma, a atual jurisprudência brasileira revela que, a despeito da ausência de estruturação enquanto instituto jurídico no Brasil, o consentimento livre e esclarecido está ganhando espaço no cenário judicial brasileiro, em função da abordagem da relação médico-paciente como uma relação de consumo.

Entretanto, o fato de o delineamento do consentimento livre e esclarecido nos tribunais brasileiros estar sendo guiado pela aplicação do Código de Defesa do Consumidor pode apresentar conflitos com a originária concepção do tema.

Observa-se, por exemplo, que a legislação consumerista admite a padronização das informações a serem prestadas ao 'consumidor médio' o que, no caso do consentimento livre e esclarecido, propicia o afastamento da concepção de informação individualizada e de comunicação entre médico e paciente.

Nesse ponto, cabe salientar que, salvo em alguns poucos julgados, a informação não é tratada como questão inerente ao contexto da tomada de decisão, de tal forma que a sua finalidade frequentemente deixa de ser associada ao processo de decisão livre e esclarecida.

Dessa forma, o foco dos tribunais parece estar mais no cumprimento do dever de informar pelo médico, enquanto prestação das informações padronizadas ao consumidor, e menos na troca de informações entre médico e paciente e na compreensão de tais informações pelo paciente.

Assim, a despeito de entendermos como positivo o reconhecimento, pelos tribunais, do direito do paciente à informação, temos que a forma com que o cumprimento do correspondente 'dever de informar' do médico é exigido afasta-se da ideia de processo de decisão livre e esclarecida.

A própria determinação amplamente verificada nos julgados estudados, no sentido de que o médico comprove ter cumprido os seus deveres de informar e de obter o consentimento através de um formulário padrão assinado pelo paciente, revela uma preocupante equiparação entre o 'consentimento 
livre e esclarecido' e o 'termo de consentimento livre e esclarecido'. Como antes verificado, o 'termo' é fruto da 'medicina defensiva', que enxerga em tal documento uma hábil ferramenta à comprovação dos deveres médicos de informar e de obter o consentimento do paciente.

Ressaltamos que a abordagem dos tribunais sobre a função dos formulários padronizados tem influência direta na prática médica. Dessa forma, a sua livre aceitação - ou até mesmo a sua exigência, como verificado em diversas decisões - pode reforçar o entendimento, pelo profissional médico, de que o consentimento livre e esclarecido consiste no ato de obter a assinatura do paciente em um formulário contendo informações padronizadas, afastando a concepção de um processo compartilhado de decisão livre e esclarecida, que pressupõe a troca de informações entre o médico e o paciente.

Similar entendimento foi verificado entre os médicos estadunidenses em pesquisas realizadas no início da década de 1980 , quando o 'consentimento informado' (informed consent) desenvolvido pelos tribunais dos Estados Unidos passou a significar para os médicos o cumprimento dos deveres de informar e de obter o consentimento do paciente.

Assim, a abordagem do 'consentimento informado' enquanto obtenção da assinatura do paciente em um formulário padrão perpetuou, entre os médicos estadunidenses, a visão do 'consentimento informado' enquanto uma imposição legal externa e desconectada da relação médico-paciente ${ }^{(69)}$.

Decorridos mais de cinquenta anos, desde a sua criação pelos tribunais estadunidenses no ano de 1957, o 'consentimento informado' permanece, nos Estados Unidos, muito mais relacionado ao 'termo' assinado do que ao processo de decisão livre e esclarecida. Nesse sentido, Ali( ${ }^{(70)}$ salienta a não concretização dos objetivos do 'consentimento informado' naquele país, em função da prevalência da abordagem do tema enquanto instrumento de exclusão de responsabilidade médica.

Verifica-se, pois, que a abordagem do consentimento livre e esclarecido enquanto mera assinatura em formulário padrão cria obstáculos ao desenvolvimento do consentimento livre e esclarecido enquanto um processo de decisão livre e esclarecida. Dessa forma, perpetua-se a limitada participação do paciente no processo de tomada de decisão, no contexto da assistência médica. ${ }^{(71)}$

Consideramos, então, que, no estágio embrionário em que se encontra a abordagem jurídica do consentimento livre e esclarecido no Brasil, revelase essencial uma maior interação entre a Bioética e o Direito, de tal sorte que

(69) APPELBAUM, P.; LIDZ, C.W.; MEISEL, A. op. cit.

(70) ALI, V. op. cit.

(71) SCHUCK, P. H. Rethinking informed consent. Yale Law Journal, v. 103, p. 900-959, Jan. 1994. 
não se concretize, aqui, o descompasso entre as abordagens ética e jurídica sobre o tema, como ocorrido nos Estados Unidos, ao longo dos cinquenta anos de existência do informed consent, conforme salientado por Ali ${ }^{(72)}$.

Nesse contexto, os tribunais brasileiros têm papel fundamental, à medida que, no caso concreto, a eles caberá delinear o consentimento livre e esclarecido enquanto questão existencial da tomada de decisão, ressaltando menos a mera transmissão de informações e a assinatura de papéis, e mais a participação do paciente, a troca de informações, e a qualidade da relação entre médico e paciente.

\section{REFERÊNCIAS BIBLIOGRÁFICAS}

AGUIAR JR, R. R. Responsabilidade civil do médico. In: TEIXEIRA, S. F. (Coord.). Direito e medicina. Belo Horizonte: Del Rey, 2000. p. 133-180.

ALI, V. Consent forms as part of the informed consent process: moving away from "medical Miranda". Hastings Law Journal, San Francisco, jul. 2003.

ALMEIDA, J. L. T. Respeito à autonomia do paciente e consentimento livre e esclarecido: uma abordagem principialista da relação médico-paciente. 1999. 129 p. Tese (Doutorado em Ciências) - Fundação Oswaldo Cruz, Escola Nacional de Saúde Pública, Rio de Janeiro, 1999.

APPELBAUM, P.; LIDZ, C.W.; MEISEL, A. Informed consent: legal theory and clinical practice. New York: Oxford University Press, 1987.

ARNOLD, R.M.; LIDZ, C.W. Informed consent - Clinical aspects of consent in healthcare. In: POST, S. G. Encyclopedia of bioethics. 3. ed. New York: Macmillan Reference, 2003. v. 3, p. 1290-1296.

BEAUCHAMP, T. L.; CHILDRESS, J. F. Princípios de ética biomédica. Tradução de L. Pudenzi. São Paulo: Loyola, 2002.

BEAUCHAMP T. L.; FADEN, R. R. Informed consent - meaning and elements. In: POST, S. G. (Ed.). Encyclopedia of bioethics. 3. ed. New York: Macmillan Reference, 2003. v. 3, p. 1277-1280.

BORGES, R. C. B. Disponibilidade dos direitos de personalidade e autonomia privada. São Paulo: Saraiva, 2005.

BRASIL. Lei n. 10.406, de 10 de janeiro de 2002. Código Civil. São Paulo: Ed. Revista dos Tribunais, 2002.

BRASIL. Lei n. 8.078, de 11 de setembro de 1990. Código de Defesa do Consumidor. São Paulo. Editora Revista dos Tribunais, 2001.

(72) ALI, V. op. cit. 
BRASIL. Lei n. 9.263, de 12 de janeiro de 1996. Regula o § $7^{\circ}$ do artigo 226 da Constituição Federal, que trata do planejamento familiar, estabelece penalidades e dá outras providências. Disponível em: <http:// www6.senado.gov.br/sicon/PreparaPesquisaLegislacao.action>. Acesso em: 16 mai. 2006.

BRASIL. Lei n. 9.434, de 4 de fevereiro de 1997. Dispõe sobre a remoção de órgãos, tecidos e partes do corpo humano para fins de transplante e tratamento e dá outras providências. Disponível em: <http://www6.senado.gov.br/sicon/ ExecutaPesquisaLegislacao.action>. Acesso em: 16 mai. 2006.

CALLAHAN, D. Bioethics and the culture wars. Cambridge Quarterly of Healthcare Ethics, New York, v. 14, n. 4, 2005.

CONSELHO FEDERAL DE MEDICINA. Resolução n. 1.358, de 11 de novembro de 1992. Adota as normas éticas para a utilização das técnicas de reprodução. Disponível em: <http://www.portalmedico.org.br/resolucoes/cfm/ 1992/1358_1992.htm>. Acesso em: 16 mai. 2006.

CREMESP - CONSELHO REGIONAL DE MEDICINA DO ESTADO DE SÃO PAULO. O médico e a justiça: um estudo sobre ações judiciais relacionadas ao exercício profissional da medicina. São Paulo, 2006.

EM DEFESA de quem? Ser médico. Revista do Conselho Regional de Medicina do Estado de São Paulo, São Paulo, n. 21, p. 24-32, out./dez. 2002.

DENÚNCIAS e processos contra médicos no Conselho Regional de Medicina do Estado de São Paulo. CREMESP (Conselho Regional de Medicina do Estado de São Paulo), 2006. Disponível em: <http://www.cremesp.org.br/ ?siteAcao=Salalmprensa\&id=131>. Acesso em: 05 fev. 2007.

DINIZ, D.; GUILHEM, D. O que é bioética. São Paulo: Brasiliense, 2002.

DINIZ, M. H. Compêndio de introdução à ciência do direito. 16. ed. São Paulo: Saraiva, 2004.

ETCHELLS, E. et al. Disclosure. In: SINGER, P.A. (Ed.). Bioethics at the bedside. Ottawa: Canadian Medical Association, 1999. p. 9-16.

FABIAN, C. O dever de informar no direito civil. São Paulo: Ed. Revista dos Tribunais, 2002.

FADEN, R. R; BEAUCHAMP, T. L. A history and theory of informed consent. New York: Oxford University Press, 1986.

FERRAZ JUNIOR, T. S. Estudos de filosofia do direito: reflexões sobre o poder, a liberdade, a justiça e o direito. São Paulo: Atlas, 2002.

FORTES, P.A.C. A responsabilidade médica nos tribunais. 1994. 199 p. Tese (Doutorado em Saúde Pública) - Faculdade de Saúde Pública, Universidade de São Paulo, São Paulo, 1994.

FORTES, P.A.C. Ética e saúde. São Paulo: EPU, 1998. 
GUZ, G. O consentimento livre e esclarecido na prática médica: um estudo da jurisprudência dos tribunais brasileiros. 2007. 147 p. Dissertação (Mestrado em Saúde Pública), Faculdade de Saúde Pública, Universidade de São Paulo, São Paulo, 2007.

KATZ, J. El médico y el paciente: su mundo silencioso. México, D.F.: Fondo de Cultura Económica, 1989.

KFOURI NETO, M. Culpa médica e ônus da prova. São Paulo: Ed. Revista dos Tribunais, 2002.

KUCZEWSKI, M.; MEISEL, A. Demystifying myths about informed consent. Forum - Risk Management Foundation of the Harvard Medical institutions, Cambridge, v. 20, n. 4, p. 1-3, summer 2000.

LIMA, J. L. B. de O consentimento informado e seu amparo constitucional. 2005. 305 p. Dissertação (Mestrado em Direito) - Faculdade de Direito, Pontifícia Universidade Católica de São Paulo, São Paulo, 2005.

MARQUES, C.L. A responsabilidade dos médicos e do hospital por falha no dever de informar ao consumidor. Revista dos Tribunais, São Paulo, ano 93, v. 827 , p. 11-48, set. 2004 .

MINISTÉRIO DA SAÚDE. Conselho Nacional de Saúde. Resolução n. 196, de 10 de outubro de 1996. Aprova diretrizes e normas regulamentadoras de pesquisas envolvendo seres humanos. Brasília: Disponível em <http:// conselho.saude.gov.br/comissao/conep/resolucao.html>. Acesso em: 14 mar. 2006.

PRESIDENT'S COMISSION FOR THE STUDY OF ETHICAL PROBLEMS IN MEDICINE AND BIOMEDICAL AND BEHAVIORAL RESEARCH. Making health care decisions: the ethical and legal implications of informed consent in the patient-practitioner relationship. Washington, 1982. $3 \mathrm{v}$.

SABINO, P. A. L. Notas acerca do valor metodológico do estudo jurisprudencial. Jus Navigandi: Teresina, ano 8, n. 352, 24 jun. 2004. Disponível em: <http://jus2.uol.com.br/doutrina/texto.asp?id=5382>. Acesso em: 02 dez. 2005.

SÃO PAULO (Estado). Lei n. 10.241, de 17 de março de 1999. Dispõe sobre os direitos dos usuários dos serviços e das ações de saúde no Estado e dá outras providências. Diário Oficial do Estado de São Paulo, São Paulo, 18 mar. 1999. Seção 1, p. 1.

SCHRAIBER, L. B. Medicina tecnológica e prática profissional contemporânea: novos desafios, outros dilemas. 1997. 205 p. Tese (Livre Docência Departamento de Medicina Preventiva) - Faculdade de Medicina, Universidade de São Paulo, São Paulo, 1997.

SCHUCK, P. H. Rethinking informed consent. Yale Law Journal, v. 103, p. 900-959, Jan. 1994. 
SIEGLER, M.; COLLINS, M. E.; CRONIN, D. C. Special challenges to the informed consent doctrine in the United States. The Journal of Clinical Ethics, v. 15, n. 1, p. 38-47, spring 2004.

SOTTO, D. O dever de informar do médico e o consentimento informado do paciente. Medidas preventivas à responsabilização pela falta ou deficiência de informação. Jus Navigandi, Teresina, ano 8, n. 178, 31 dez. 2003. Disponível em: <http://www1.jus.com.br/doutrina/texto.asp?id=4635>. Acesso em: 12 dez. 2004.

SZTAJN, R. Consentimento informado e o projeto de Código Civil. Revista de Direito Mercantil Industrial, Econômico e Financeiro, São Paulo, n. 109, p. 93-97, jan./mar. 1998.

VIEIRA, S; HOSSNE, W. S. Experimentação com seres humanos. 2. ed. São Paulo: Moderna, 1987. 